\section{La trama social de la economía popular en el Conurbano bonaerense. Algunas precisiones conceptuales}

Marcela Vio

María Claudia Cabrera

Docentes investigadoras de la Universidad Nacional de Avellaneda, Argentina
Economía Social y Solidaria /

Perspectivas

RECEPCIÓN: 23/06/15

ACEPTACIÓN FINAL: 20/08/15

\section{Resumen}

Este trabajo presenta algunas conceptualizaciones surgidas de una investigación iniciada en el año 2011 en el marco de un convenio entre el Ministerio de Desarrollo Social de la Provincia de Buenos Aires y la Universidad Nacional de Avellaneda y que continúa hasta el presente en esa Universidad. La misma tiene por objeto estudiar la economía popular realmente existente. Se presentan las dos posiciones que asumen las discusiones sobre la economía popular en la academia y se sitúa la propia investigación en función de esas posiciones. En esta discusión se jerarquiza la evidencia empírica, por lo que se avanza en reflexiones que apuntan a poner en el centro de la escena cuestiones teórico-metodológicas para el estudio de esa economía realmente existente. Puntualmente, se profundiza en las estrategias de reproducción social de los sectores populares y se propone el estudio de cuatro de ellas: las que procuran obtención de bienes de uso, obtención de ingresos, acceso al financiamiento y acumulación de un "fondo de reproducción" de los hogares.

\section{Palabras clave}

- economía popular

- estrategias de reproducción social

- sectores populares

- territorio

\section{Resumo}

Este artigo apresenta algumas conceituações decorrentes de uma investigação lançada em 2011, no ámbito de um acordo entre o Ministério de Desenvolvimento Social da Província de Buenos Aires e a Universidade Nacional de Avellaneda, e que continua até hoje nessa Universidade. É ela quem tem como objetivo estudar a economia popular existente. Portanto se apresentam as duas posições que assumem os argumentos sobre a economia popular na academia e situa-se a própria pesquisa na função dessas posições. Nesta discussão se categoriza a evidência empírica, motivo pelo qual se avança em reflexões que colocam no centro da cena questões teórico-metodológicas para o estudo dessa economia existente. Prontamente se aprofunda nas estratégias de reprodução social dos sectores populares, propondo o estudo de quatro delas: no intuito de obter ativos, geração de renda, acesso ao financiamento e criar um "fundo de reprodução" das famílias.

Palavras-chave

- economia popular

- estratégias de reprodução social

- setores populares

- território

Para citación de este artículo

Vio, M. y Cabrera, M. C. (2015). La trama social de la economía popular en el Conurbano bonaerense. En Revista

+E versión digital, (5), pp. 60-67. Santa Fe, Argentina: Ediciones UNL. 
las actuales discusiones sobre

la economía popular giran en torno a dos

posiciones que proponen el análisis

de lo que denominan economía social

\section{Introducción}

Este artículo presenta resultados de una investigación iniciada en 2011 y que continúa en desarrollo. Uno de sus objetivos ha sido la producción de datos primarios de barrios populares del Conurbano bonaerense: a la fecha se han relevado mediante una encuesta representativa de cada uno de los 12 barrios pertenecientes a ocho municipios, lo que brinda datos ponderados de más de 60 000 personas y 13000 viviendas y hogares, y se han realizado 125 entrevistas en profundidad a sus habitantes.

Uno de los resultados obtenidos es un avance en el análisis conceptual de esas estrategias, en tanto cabe señalar que existen cuatro tipos de ellas. Las dos primeras son habitualmente consideradas por la literatura académica, mientras que contemplamos a las dos últimas como un aporte de los hallazgos empíricos y conceptuales del desarrollo de nuestro trabajo. Las estrategias estudiadas son las de obtención de bienes y de obtención de ingresos. La tercera estrategia, que en los sectores populares no puede reducirse a las dos primeras, se deslinda de las anteriores por tener una racionalidad propia: nos referimos a las estrategias para la obtención de financiamiento. Finalmente, la cuarta que estudiamos es la que propone un acrecentamiento del fondo de reproducción de los hogares.

Este artículo se estructura en dos apartados. En el primero

ubicaremos la investigación que se presenta respecto de las actuales discusiones y posicionamientos teóricos sobre la economía popular. En el segundo comentaremos las estrategias de reproducción social de los sectores populares en estudio, de acuerdo con nuestros hallazgos empíricos. Nos detendremos en las dos últimas que, como se señala arriba, son parte de los aportes conceptuales de la investigación. Y concluiremos con unas breves reflexiones.

\section{Economía social y economía popular}

Las actuales discusiones sobre la economía popular giran en torno a dos posiciones que proponen el análisis de lo que denominan economía social. Por un lado, aquellas que se formulan con carácter de proposición, que enlazan su análisis con otras formas de organización económica (no capitalistas), tales como la economía social o solidaria, y orientan el debate hacia la formación de un sector urbano de resistencia que pueda sobreponerse a los avatares de la racionalidad capitalista, garantizando su reproducción ampliada. Podemos encolumnar las propuestas de Coraggio (2004), Quijano (2007) e Icaza y Tiriba (2004) en esta primera postura. Por otro lado, las discusiones que procuran aportar una caracterización a la luz de la evidencia empírica, para las cuales una parte creciente de los sectores pobres urbanos sostiene su integración social por fuera de las protecciones del trabajo asalariado y satisface el consumo de valores de uso, básicos para la reproducción de la vida, por otras vías además de la mercantil. Razzeto (1993) y Hintze (2004) representan estas posiciones.

El punto de encuentro $y$, a la vez, el de partida, de ambas vertientes se da en la concepción de la economía popular y social-solidaria como una dimensión específica de la organización social y económica que trasciende la lógica de la ganancia y se vincula a la reproducción ampliada de la vida. Del mismo modo, ambos enfoques advierten la presencia de mecanismos de reciprocidad y solidaridad que representan formas específicas de integración e intercambio y configuran formas de protección alternativas a las del trabajo asalariado lo que, para el debate en curso, resulta habilitante de la relación directa entre economía popular y economía social o solidaria. 
De acuerdo con algunos autores que indagan en esta relación, los actores de la economía popular desarrollan estrategias de trabajo y supervivencia que buscan, no sólo la obtención de ganancias monetarias y excedentes que puedan ser intercambiados en el mercado, sino también la creación de condiciones que favorezcan algunos elementos que son fundamentales en el proceso de formación humana, como la socialización del conocimiento y de la cultura, la salud, la vivienda, etc. Así, las actividades de la economía popular incluyen tanto a las iniciativas económicas destinadas a la obtención inmediata de ingresos como a las acciones espontáneas de familiares, amigos y vecinos, y las colectivas —organizadas en el ámbito de la comunidad-, que tienen como meta una mejor calidad de vida. Entre estas actividades grupales se destacan las orientadas a la construcción de viviendas, el cuidado de niños y adultos mayores y la realización de trabajos de reparación barrial (Coraggio 2004; Icaza y Tiriba, 2004).

En esta línea, Icaza y Tiriba (2004) plantea que esta economía, en contraposición a la capitalista, se funda en el hecho de que los trabajadores no intercambian su fuerza de trabajo por un salario (lo que supondría la existencia de un trabajo pago junto con uno excedente, no remunerado). Para las autoras, los trabajadores de la economía popular tienen la posesión de los medios de producción y se valen por principio de la utilización del trabajo propio para garantizar, no sólo la subsistencia inmediata, sino también la producción de un excedente que pueda ser intercambiado en el mercado por otros valores de uso. El trabajo es, sin dudas, el principal factor de producción. En este sentido, la racionalidad interna de esta economía supone la negación del vínculo empleador-empleado.

Por su parte, Coraggio (2004) sostiene que, aun en contextos de existencia de trabajo asalariado, el objetivo de la economía popular sigue siendo la reproducción ampliada de la vida. En su propuesta de una economía centrada en el trabajo reconoce las diversas formas que éste puede asumir; así distingue entre: trabajo de reproducción, mercantil, dependiente asalariado, de formación y comunitario. En tanto, Razzeto (1993) postula que la economía popular es un fenómeno generalizado que tiene lugar en los países latinoamericanos y está presente en las unidades económicas manejadas a nivel individual, familiar o en grupos, y el cual está compuesto, básicamente, de cinco tipos de actividades vinculadas a la mendicidad, prácticas mercantiles ilegales, y trabajo cuentapropista que abarca también a las microempresas familiares y a las organizaciones asociativas cooperativas.

Existe una tercera corriente que se alinea en las visiones que proponen una economía social y solidaria, nos referimos a aquellas que encuentran nuevas modalidades de organización del trabajo en la autogestión. Las empresas recuperadas ocupan el centro de los análisis de estos trabajos que postulan estos procesos como pertenecientes a una lógica de la economía social (Rebón, 2004; Rebón y Saavedra, 2006).
Nuestra perspectiva se acerca a las visiones que exploran principalmente las modalidades de producción, consumo e intercambio de los sectores populares en coincidencia con algunos de los principios que propone la segunda de las vertientes del debate que mencionamos antes. Fundamentalmente, acordamos con estas visiones en la jerarquización de la evidencia empírica para el estudio de la economía popular. Sin embargo, nos alejamos de las proposiciones que muchos de estos trabajos contienen ya que nuestra perspectiva se sitúa en la economía popular realmente existente. Nuestro objetivo es estudiar las estrategias de reproducción social a partir de la ampliación del conocimiento empírico de los sectores populares. En este sentido, y desde una perspectiva teórico-metodológica, aportaremos a continuación algunas conceptualizaciones que son los primeros hallazgos del proceso de investigación de esta economía popular que desde el enfoque que se propone, encuentra pocos antecedentes de investigación, lo que nos ha obligado a la producción de categorías conceptuales nuevas dada la insuficiencia de las existentes para el estudio de la economía popular.

Esta perspectiva nos aleja también de aquellos que hacen del fenómeno de la pobreza el elemento que recorta sus universos de estudio. En nuestro caso, el criterio de recorte surge de una estrategia de reproducción de un sector de los hogares de la economía popular; nos referimos específicamente a aquella que resuelve el acceso a la tierra y la vivienda por fuera del mercado formal.

\section{La economía popular realmente existente: algunos conceptos para su análisis}

En trabajos anteriores (Cabrera y Vio, 2014) hemos desarrollado algunos acercamientos conceptuales que queremos retomar y profundizar aquí, al igual que presentar algunas cuestiones teóricometodológicas para el estudio empírico de la economía popular. En primer lugar, es necesario explicitar el criterio de recorte del universo en estudio, a partir del cual nos propusimos conjurar varios riesgos. El primero de ellos es el que presentan los reduccionismos geográficos al definir el universo por el lugar que se habita (es decir, villas y asentamientos), considerando así el recorte geográfico como determinante de las condiciones de vida. También esperamos escapar de otro riesgo metodológico: el de recortar la pobreza como universo de estudio para comprobar que encontramos allí a los pobres. Y finalmente, al elegir situar nuestra mirada en las estrategias de reproducción social y no en las percepciones sociales sobre los pobres, esperamos escapar de un sesgo de clase: el de las miradas condescendientes sobre ellos. Para los hogares de la economía popular la vivienda se convierte en un bien de uso central para la vida familiar, cuya producción moldea la organización del trabajo doméstico, convoca la ayuda de familiares, amigos y vecinos, e involucra una parte significativa del ingreso del hogar, reduciendo las posibilidades de gasto para la 
obtención de otros bienes. Nuestro criterio de recorte recupera esa centralidad, por lo que la estrategia que consideramos definitoria para ello es aquella que resuelve ese acceso a la tierra y a la vivienda por fuera del mercado inmobiliario formal. Ello contempla entonces a los hogares que habitan en villas y asentamientos, como también en barrios construidos por la política estatal de vivienda (que incluye la vivienda social y a los Núcleos Habitacionales Transitorios), como aquellos que se asentaron en barrios originados en loteos populares pero que luego se densificaron a partir de la usurpación de lotes originariamente de amplias dimensiones. Se establece así una diferenciación con otros grupos dentro del universo de sectores populares. Esto se debe a que la estrategia reproductiva (orientada a la obtención de suelo y vivienda) se distingue de aquella que llevan adelante los otros grupos mencionados, principalmente por el carácter informal de los intercambios que median el acceso al suelo y a la vivienda, en particular con otros hogares/agentes de la economía popular, y por los intercambios (formales) con el Estado, los que también marcan la distancia respecto de los primeros, para los cuales dicha estrategia se expresa principalmente en la adquisición a partir de operaciones de compra y venta en el mercado inmobiliario (formal). Determinado así el universo, se puede avanzar en una reflexión acerca de las "clases populares". Adamovsy (2012) ensaya una aproximación a su conceptualización en tanto, como toda clase, abarca a un conjunto "múltiple y heterogéneo de grupos sociales". Pero existen varios aspectos que permiten unificar esa multiplicidad y heterogeneidad. Por un lado, estos grupos "se fueron haciendo parte de una misma sociedad", en coincidencia con la postura ya señalada según la cual no es posible pensarlos excluidos de ella. La segunda característica, definitoria para el autor, es la posición subalterna compartida por ese conjunto. En términos de Pierre Bourdieu, su exclusión del campo del poder. Esta relación fundamental de subordinación es lo que define a este grupo como clase. Sin embargo, la posición subordinada —que implica una definición por la negativa - es una condición necesaria pero no suficiente para delimitar las fronteras que permiten hablar de clases populares.

Así que a estas dos características definitorias de las clases populares sumamos una tercera, que recupera uno los principios epistemológicos fundamentales de la sociología y que ha reafirmado Bourdieu en sus trabajos: las clases sociales existen objetivamente. Esta objetividad corresponde a clases de condiciones de existencia establecidas por la posición que ocupan en el espacio social, posición determinada, a su vez, por la composición y estructura del capital que posee y acumula cada grupo social (Bourdieu, 1988; 2000).

La pertenencia a las distintas clases puede operacionalizarse a partir de las prácticas y de las propiedades de los agentes que la constituyen, propiedades en todos sus sentidos ${ }^{1}$ : como posesiones y como cualidades. Las prácticas se realizan en las estrategias

de los hogares que analizamos en varios trabajos anteriores (Cabrera y Vio, 2014; Cabrera, 2014a; Cabrera, 2014b; Vio, 2014; Zuchiatti, 2014). Respecto de las propiedades, sin jerarquizar ni establecer determinantes, podemos mencionar algunas: escasas credenciales educativas, trabajadores con acceso a trabajos informales, poco calificados y mal pagos, condiciones de hábitat deficitario, fuerte presencia de condiciones de pobreza por ingresos y pobreza estructural.

Partimos de la afirmación de Adamovsky (2012) para estudiar a uno de estos grupos que se distancia de otros grupos populares urbanos. Este postulado se funda en la interpretación de una dimensión del proceso sociourbano que tiene lugar en el Conurbano bonaerense, del cual el grupo que nos interesa participa, y es en el marco donde podemos ensayar algunas explicaciones que den cuenta de sus rasgos particulares; dicho en otras palabras, de aquellas características que lo apartan de otros grupos también populares. Más concretamente, es posible encontrar las especificidades de este grupo como una clase dentro de las clases populares, viendo el modo en que se constituyen en el marco de la relación sociedad, economía y territorio. Es decir que una primera distinción puede fundarse en el modo que en tanto grupo popular dentro del conjunto social metropolitano, dialoga con la economía y el territorio. Pero ello es insuficiente para avanzar en su recorte como clase, es necesario responder a la pregunta acerca de qué los aglutina como tal. Y la respuesta nos acerca a un recorte teórico de nuestro universo: los aglutina un modo singular de relación con el Estado, una ubicación subalterna en el espacio geográfico y un modo de inserción en la estructura productiva excluida de los parámetros de la sociedad salarial (Castel, 1997) pero no por ello sin funcionalidad al desarrollo capitalista. Otro de los conceptos en los que ancla nuestra investigación es el de "economía popular", a la que hemos definido como "una matriz específica de estrategias", caracterizada por la pérdida de peso del trabajo mercantil en la provisión de satisfactores (sin dejar de ser la principal fuente de ingresos), la imbricación del trabajo doméstico con las estrategias de obtención de ingresos para asegurar la reproducción, fuerte incidencia de las transferencias monetarias estatales de ingresos para asegurar la reproducción (esta última es una de las resultantes de las reconfiguración de la economía popular en la posconvertibilidad), el deslinde del financiamiento como una estrategia con racionalidad propia, la constitución de un fondo de reproducción que involucra a todos los miembros del hogar (en otros

1) Según el Diccionario de la Real Academia Española (RAE), el término "propiedad" tiene las siguientes acepciones: Derecho o facultad de poseer alguien algo y poder disponer de ello dentro de los límites legales. / Cosa que es objeto del dominio, sobre todo si es inmueble o raíz. / Atributo o cualidad esencial de alguien o algo 
sectores sociales esta estrategia se manifiesta como capital social, y si bien se explica por la posición en el espacio social de quienes los ponen en juego, su utilización se presenta en las interacciones como un capital de los individuos).

Cabe una aclaración de carácter teórico-metodológico: al analizar una matriz de estrategias (ya que cada clase social tiene su propia matriz) es necesario reflexionar sobre aquello que es específico de ella y aquello que es general a la sociedad, pues evita así atribuir a ellas lo que tiene que ver con la sociabilidad. Pero nos permite también objetivar nuestra propia posición de clase (media, propia de la academia) y encontrar en ella las estrategias, propiedades y racionalidades que suelen atribuirse, habitualmente con una mirada moralista, exclusivamente a los sectores populares.

Considerando entonces esta cuestión de la especificidad, afirmamos que la "inscripción territorial" no es una característica propia de los sectores populares - en todos los sectores sociales la vida social está moldeada por relaciones sociales inscriptas territorialmente, aunque es cierto que puede haber diferentes intensidades- sino de su economía.

En general, la economía popular encuentra en el territorio sus condiciones de posibilidad. Es decir, no es posible explicar las especificidades de las estrategias de reproducción por fuera de los territorios que los hogares habitan. No se puede dar cuenta de las condiciones de reproducción de barrios como Costa Esperanza o Independencia en San Martín sin considerar la presencia de la CEAMSE, ${ }^{2}$ como tampoco las de Las Achiras en La Matanza sin tener en cuenta al Mercado Central o La Salada. ${ }^{3} \mathrm{O}$ las condiciones de vida de San Cayetano/San Blas en San Miguel o 22 de Enero en La Matanza sin pensar a esos barrios como enclaves de especialización productiva. Y también a esta fracción de los sectores populares la aglutina una particular forma de relación con el Estado, que es de subordinación y dependencia, no puede dejar de considerarse la manera en que las matrices político-territoriales son definitorias de las condiciones de vida.

Ellas están fundadas en el amalgamamiento del poder estatal con el de las organizaciones de base y con los poderes individuales de los "referentes comunitarios y barriales". Esta "fusión" de poderes diversos es posible a partir de las transferencias de diversos tipos de capital —bienes de uso/dinero/social/simbólico— que son asignados en función de la forma que asume la articulación entre la matriz político-territorial y los fondos de reproducción de los hogares (Cabrera y Vio, 2014).

Otra característica de la matriz de estrategias de la economía popular es el modo enmarañado en el que se vinculan unas con
2) Coordinación Ecológica Área Metropolitana Sociedad del Estado, com puesta por los gobiernos de la Ciudad y la Provincia de Buenos Aires, que comenzó a encargarse de transportar de los residuos desde las zonas de acopio y realizar su disposición final. 3) Se trata de una feria informal de magnitud extraordinaria, lo que la convierte en una de las más grandes del mundo, o probablemente la mayor. 


\section{6}

\section{para los hogares de la economía popular \\ la vivienda se convierte en un bien de uso central para la vida familiar, cuya producción moldea la organización del trabajo doméstico}

otras, lo que hace difícil definir con claridad los límites. En otros sectores sociales claramente las estrategias de obtención de ingresos a través del trabajo mercantil definen los modos de acceso a bienes de uso y a financiamientos. Pero en la economía popular las estrategias se traslapan y confunden unas con otras. Mencionamos que en la economía popular estas estrategias pueden agruparse en cuatro tipos: aquellas que apuntan a la obtención de bienes de uso, las que procuran obtener ingresos, las que buscan obtener financiamiento y las que se proponen acrecentar el "fondo de reproducción" de los hogares. Por razones de espacio sólo nos extenderemos en las dos últimas, ya que ellas son distintivas de la economía popular.

Al pensar en financiamiento, no lo hacemos en clave al financiamiento producto a través de los microcréditos. Este tipo de financiamiento es casi inexistente en el universo que analizamos, aunque es objeto frecuente de los análisis académicos. Sin embargo, el financiamiento realmente existente en los sectores populares es en general ignorado, salvo algunas pocas excepciones (Wilkis, 2012; Cabrera, 2014a).

Señalamos que esta estrategia mantiene una racionalidad propia que no puede ser equiparada a las otras estrategias de reproducción social. Cabe recordar que el criterio de recorte de nuestro universo incorpora las estrategias de acceso a la tierra y a la vivienda. Al desarrollarse por fuera del mercado formal, priman condiciones de informalidad respecto de la cuestión jurídica de la tenencia. Ello es un primer obstáculo que debe considerarse cuando se analizan los modos del financiamiento de la economía popular. El otro es la extensión del trabajo informal (no registrados y cuenta propia), que en todos los casos analizados es el de la mayoría. Y éste se constituye en un segundo obstáculo para acceder al financiamiento del sistema financiero.

De acuerdo con los hallazgos de la investigación, en la economía popular conviven:

- el financiamiento a partir de fuentes externas a las redes domésticas a las que se puede recurrir a cambio del pago de un interés considerable (préstamos bancarios personales y prestamistas); - modalidades que articulan las redes territoriales con el financiamiento, incluyendo a familiares, amigos, vecinos y patrones del trabajo;

- aquellas que se desarrollan a partir de un "redireccionamiento" de las políticas sociales de transferencias monetarias, ya que los hogares mantienen otras estrategias (previas) de acceso a bienes de uso y financiamiento (cuando los había) y destinan los ingresos de las políticas sociales a financiar la construcción o el mejoramiento de la vivienda (Cabrera, 2014a).

Respecto de las estrategias de ampliación del "fondo de reproducción de los hogares", nos referimos a aquellas que se dirigen al sostenimiento y ampliación del capital social o sistema de relaciones en que se inserta el hogar, en las que se pone en juego la construcción de vínculos (de solidaridad o dependencia) que ofrezcan garantías a la reproducción y retroalimenten las posibilidades de reproducción ampliada de las condiciones de vida. Lo anterior supone la participación consciente en este sistema de relaciones en el que se articulan vínculos familiares y vecinales, también jerárquicos, con frecuencia atravesada por la inscripción político-territorial como matriz de mediación entre los destinatarios y los otorgadores de los recursos Estatales, que usualmente 
provienen de las políticas sociales. Estas matrices se convierten así en las reales "asignadoras" de las transferencias monetarias del Estado y de las políticas sociales en general (Cabrera, 2014b). Una característica específica del fondo de reproducción es que reclama la presencia y las acciones de las personas en las actividades que el referente territorial les "señala y exige". Es decir, su presencia en actos, en reuniones organizadas por la gestión local, provincial, municipal, nacional. De esta manera, estas personas funcionan como un "ejército simbólico" que expresa el poder territorial del referente, el cual es medido a partir de su capacidad de convocatoria.

En este sentido, se trata de un modo de trabajo diferente del que se invierte en la obtención de bienes de uso, ingresos o financiamiento. Así, el carácter inmaterial y simbólico del fondo de reproducción se traduce en un compromiso de presencia y esfuerzo, que habitualmente se articula con la estructura familiar que procesa la participación en redes populares. Estas redes deben entenderse como matrices territoriales estructuradas jerárquicamente y sostenidas en relaciones de proximidad por parentesco o vecindad, las cuales son fuente, a la vez que productoras de reciprocidades, y también de solidaridades que, sin suponer la horizontalidad de los vínculos, conforman el proceso de obtención de conocimientos y/o información, bienes, servicios e ingresos necesarios para la vida.

\section{Reflexiones finales}

En este artículo nos propusimos brindar un panorama general de los principales hallazgos conceptuales en torno a nuestro objeto de investigación, las condiciones de vida y las estrategias de reproducción social de los hogares pobres que habitan en villas, asentamientos y otros barrios populares del Conurbano bonaerense. La producción de categorías conceptuales originales se impuso como una necesidad para la continuación de nuestro trabajo, habida cuenta de que las vigentes no alcanzaban para explicar aquello que había motivado nuestro interés en esta investigación. Por eso acudimos a la noción de economía popular, advirtiendo los antecedentes en este debate, y al mismo tiempo fijando posición respecto de lo que para nosotros existe hoy como universo tangible de esta economía en los partidos del primer y segundo cordón del Gran Buenos Aires, en un intento por marcar cuáles son los bordes más nítidos que lo separa de otras clases populares, cohabitantes del mismo aglomerado. De allí que esta primera categoría nos haya permitido pensar a este grupo no exclusivamente por su posición en el espacio social, como clase subalterna, ni por su posición en el espacio geográfico como "ocupantes informales" de sectores urbanos en situación de riesgo ambiental o distantes de las áreas de centralidad, sino a partir de sus estrategias económicas, de producción y reproducción, seguros de que allí estaba el hilo conductor de esta reflexión y la posibilidad de construir a este grupo como clase.

Sólo a partir de poner las estrategias económicas en el centro pudimos volver a leer su posición en el espacio urbano como una de sus propiedades específicas en tanto ésta resulta principalmente de una práctica de intercambios sostenida en acuerdos informales al interior del propio hogar, con otros hogares y otros agentes de la economía popular (loteadores informales, a modo de ejemplo), pero que no se reducen sólo a la esfera de la informalidad, cuando articulan con el Estado y devienen en destinatarios de la política pública habitacional. En otras palabras es el distanciamiento de esta estrategia orientada a la obtención de suelo y vivienda de aquellas habituales de compra-venta en el mercado formal que siguen otras clases populares, y también dominantes, lo que le otorga a nuestro objeto empírico el gen de clase.

De la información obtenida del trabajo de campo, y por la magnitud de la muestra, se desprenden un conjunto de hipótesis de carácter general, y ahora de trabajo, que sostienen nuestra expectativa de orientar futuros estudios dentro del mismo campo. A saber, que no es la sociabilidad de este grupo aquello que está territorializado, y que otros trabajos han postulado y conceptualizado en términos de insularización o segregación socioespacial, sino que es su economía la que se inscribe territorialmente, que es parte de su sociabilidad pero no debe confundirse con ella. Es decir, son sus modos de acceder a satisfactores: bienes, servicios, dinero, políticas sociales, aquello que está fuertemente ligado a su inscripción territorial, no ya por las características de ese espacio geográfico en el que se sitúan, sino por las redes de relaciones de proximidad que estructuran otros modos de subalternidad $y$ dan lugar a la aparición de otras formas de trabajo y de nuevos satisfactores. Nos referimos especialmente a dos formas, prácticas económicas que perfilan a la matriz que sirve para explicar nuestro objeto y que constituyen el principal hallazgo de esta investigación: a) las que buscan el acceso al financiamiento que ponen en evidencia una racionalidad propia y diferente de aquellas por las que obtienen otros ingresos, bienes y/o servicios, y b) las que intentan reproducir las condiciones de vida bajo las cuales pueden realizar sus estrategias económicas, esto es, las condiciones actuales de existencia. Éstas son las que habilitan otras formas de trabajo, que también la producción académica ha gustado en llamar "prácticas clientelares" pero que en el marco de esta investigación pensamos como formas propias de esta economía popular, que marcan otros modos de subalternidad, y otros modos de trabajo, de participación presencial en espacios político-territoriales en los que se concretan las formas (secundarias) de distribución del ingreso que propicia el Estado, o en su defecto se dirimen nuevas oportunidades de acceder a dicha distribución. 


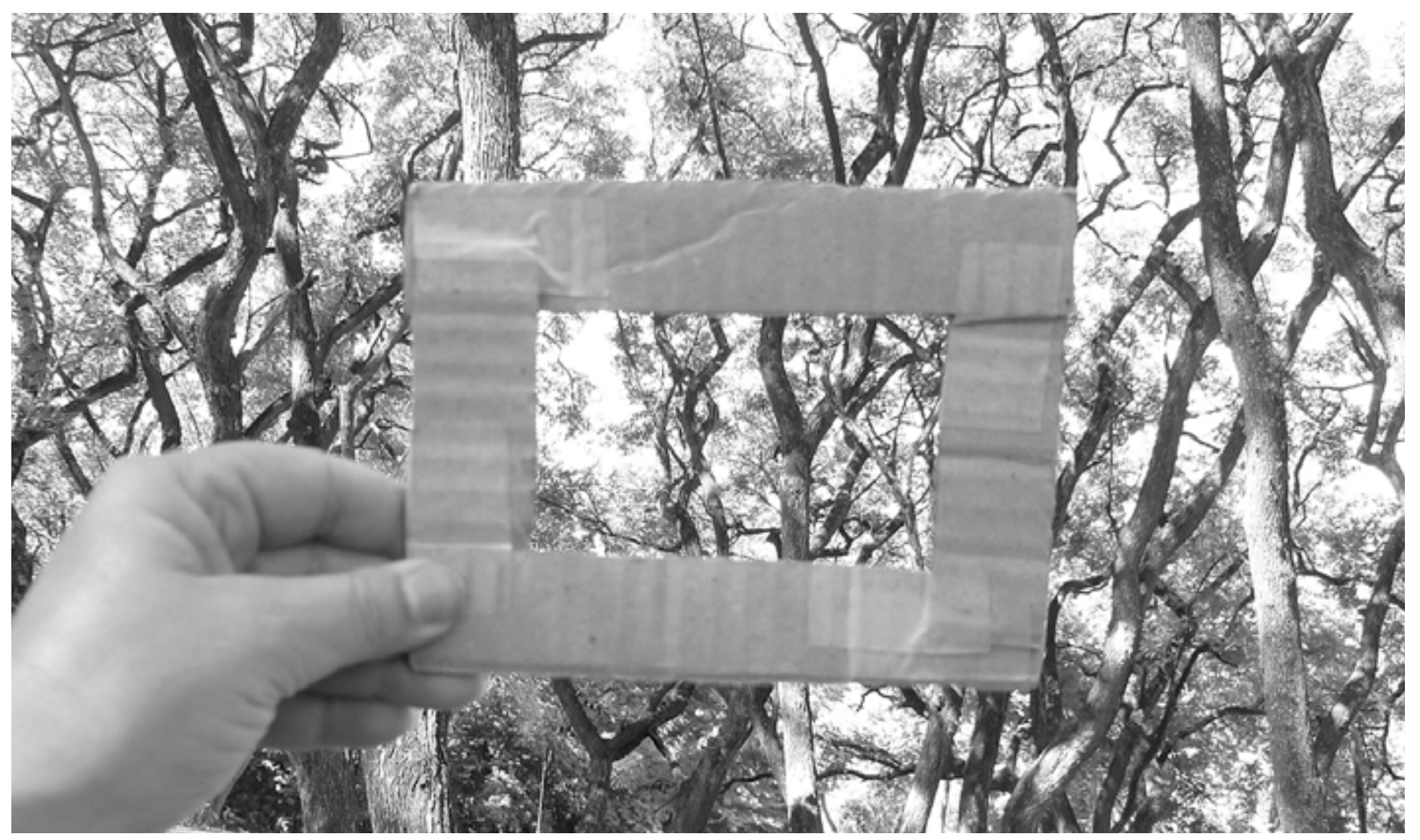

\section{Referencias bibliográficas}

Adamovsky, E. (2012). Historia de las clases populares en la Argentina ( $2^{\circ}$ reedición). Buenos Aires: Sudamericana.

Bourdieu, P. (1988/2000). Espacio social y Poder simbólico. En Bourdieu, P. Cosas dichas (trad. M. Mizraji, $2^{\circ}$ reimpresión, 127-142). Barcelona: Gedisa. Cabrera, M.C. (2014a). Hoy no se fía, mañana sí. El financiamiento de la vivienda en la economía popular. En Cabrera, M.C. \& Vio, M. (eds.), La trama social de la economía popular. Buenos Aires: Espacio.

Cabrera, M.C. (2014b). Entre dos aguas. Tensiones entre la memoria del plan y la ampliación de derechos en la implementación de las políticas sociales en el Conurbano Boanerense. En Cabrera, M.C. \& Vio, M. (eds.), La trama de la economia popular. Buenos Aires: Espacio.

Cabrera, M.C. y Vio, M. (2014). Cuadernos de Bitácora. Los hilos de la economía popular en la posconvertibilidad. En Cabrera, M.C. \& Vio, M. (eds.), La trama social de la economía popular. Buenos Aires: Espacio.

Castel, R. (1997). Las metamorfosis de la cuestión social. Una crónica del salariado (trad. J. Piatigorsky,). Buenos Aires: Paidós.

Coraggio, J.L. (2004). Economia del trabajo. En Cattani, D., La otra economia. Buenos Aires: Altamira.
Hintze, S. (2004). Capital social y estrategias de supervivencia. Reflexiones sobre el capital social de los pobres. En Danani, C., Política Social y Economía Social: debates fundamentales. Buenos Aires: Altamira.

Icaza, A.M., y Tiriba, L. (2004). Economía popular. En Cattani, A. D., La otra economía. Buenos Aires: Altamira.

Quijano, A. (2007). ¿Sistemas alternativos de producción? En Coraggio, J.L., Economía solidaria y subjetividad (145-164). Buenos Aires: Altamira.

Razeto, L. (1993). Debate comunicando acerca de la llamada economia popular. Comunicado. Boletín de Informaciones Interorganizacionales, (24).

Rebón, J. (2004). Desobedeciendo al desempleo. La experiencia de las empresas recuperadas. Buenos Aires: Ediciones PICASo/La Rosa Blindada.

Rebón, J. y Saavedra, I. (2006). Empresas recuperadas. La autogestión de los trabajadores. Buenos Aires: Capital Intelectual.

Wilkis, A. (2012). Las sospechas del dinero. Moral y economía en la vida popular. Buenos Aires: Paidós.

Zucchiatti, N. (2014). Extramuros del mercado. El entramado de la economía popular en torno al Estado y la familia. En Cabrera, M.C. \& Vio, M. (eds.), La trama social de la economía popular. Buenos Aires: Espacio. 